\title{
A New Perspective of Attention Deficit Hyperactivity Disorder Associated With Delayed Language Development: An Egyptian Sample
}

\author{
Reham Ahmed Fahiem $\bowtie$ and Lamis H Mekkawy \\ Department of Medical Studies for Children, Faculty of Postgraduate Childhood Studies, Ain Shams University, Cairo, Egypt
}

Objective The current study aimed to get an easy objective method to detect attention deficit hyperactivity disorder (ADHD) by investigating the simple inflammatory blood ratios platelet/lymphocyte ratio (PRL), neutrophil/lymphocyte ratio (NLR) \& the monocyte/lymphocyte ratio (MLR), for the sake of receiving early management to such cases and overcoming language affection as a comorbid symptom.

Methods This study was conducted on two groups: Group 1 (SG) consisted of 70 ADHD children who had delayed language development (DLD), freshly diagnosed, according to DSM-V criteria, and those patients were not on medical treatment. Group 2 healthy group (HG) consisted of 44 healthy control normal children that were both physically and mentally free of the same socio-demographic characters of the first group.

Results The PLR, NLR and MLR, were significantly higher in the ADHD group than the healthy control group (HG) group, although the simple blood indices were average.

Conclusion Inflammation has a role as a comorbid cause of ADHD. Simple blood inflammatory mediators may be used as comorbid factors in ADHD. This study explained that the language abilities must be taken in consideration when assessing children with ADHD. The screening tools for inflammatory markers are important when dealing with ADHD children with/ without delayed language development (DLD). Also, working memory assessment is mandatory in ADHD with DLD to assign a special program in language therapy for each child.

Psychiatry Investig 2022;19(3):164-170

Keywords Attention-deficit hyperactivity disorder; Inflammation; Simple blood inflammatory mediators; Inattention; Comorbid; Delayed language development.

\section{INTRODUCTION}

Delayed language development (DLD) is comorbid with behavioral problems and psychiatric disorders. ${ }^{1}$ Attention deficit hyperactivity disorder (ADHD), is considered one of the commonest psychiatric disorders, affects $5.9 \%-7.1 \%$ of childhood worldwide, ${ }^{2}$ and the disorder may continue throughout the whole lifespan. ${ }^{3}$

$\mathrm{ADHD}$ is a neuropsychiatric disorder diagnosed according to the Diagnostic and Statistical Manual of mental disor-

\footnotetext{
Received: July 12, 2021 Revised: September 13, 2021 Accepted: October 4, 2021

$\triangle$ Correspondence: Reham Ahmed Fahiem, MD Department of Medical Studies for Children, Faculty of Postgraduate Childhood Studies, Ain Shams University, Cairo, Egypt Tel: +00201111117254, E-mail: rahoma2006@hotmail.com

(c) This is an Open Access article distributed under the terms of the Creative Commons Attribution Non-Commercial License (https://creativecommons.org/licenses/bync/4.0) which permits unrestricted non-commercial use, distribution, and reproduction in any medium, provided the original work is properly cited.
}

ders-Fifth edition (DSM-5). ${ }^{4}$ Symptoms of ADHD usually start before the age of 12 , and it has to be observed in at least two settings. ${ }^{3}$

ADHD is accompanied by marked impairment of sociointeractive, and academic functioning throughout the whole life. ${ }^{4}$ The ADHD children have problems in functional areas associated with deficits in language skills, ${ }^{5}$ like frequently switching topics of conversation, sequencing difficulties, poor problem-solving skills, giving responses unrelated to questions asked, pragmatic language skills, and following directions. ${ }^{5}$ Early management will reduce the severity of symptoms and help managing the motor and language difficulties. ${ }^{6}$

Despite that the actual causative factors, pathology, and physiology of ADHD are still vague, immunity is assumed to play an essential role in their central nervous system and behavior. ${ }^{7}$

ADHD is accompanied by dysfunction in structural and functional brain areas and domains. ${ }^{8}$ Elevated association with immune-linked conditions, assuming the possibility of the 
critical role of immunity in ADHD. ${ }^{8}$ Some studies have reported high inflammatory markers in children suffering from anxiety disorders and ADHD. ${ }^{9}$ Darwish et al., ${ }^{10}$ announced that there was an elevation in the inflammatory blood markers in these children and denoted that the relation between ADHD symptoms scores and interleukins (IL-6), C-reactive protein (CRP), and tumar necrotic factor- $\alpha$ (TNF- $\alpha$ ) are non-significant.

Premature birth, as well as neonatal infections, play a condemning role in developing ADHD. Microglia cells are the dominant immunity cells in the brain. Activation of those cells results in releasing provocative cytokines and different glutamate elements, contributing to neuro-inflammation. Recently, crosslinking between the immune cells and microglia can initiate an inflammatory process in the body and the brain. ${ }^{11}$ Studies have also proved that vagal afferent fibers become indirectly activated through cytokines. ${ }^{12}$

In inflammation, leukocytes play a dominant role, and thus, variability in the leukocytic count has a significant impact on immunity during inflammation. The (NLR) obtained from the white blood cells (WBCs) count is cheap, easy, applicable, and has gained attention as a predicting tool for inflammatory and neuro-immune conditions. ${ }^{13}$

Neutrophils are the first defense line in the immune system, secreting different inflammatory mediators resulting in phagocytosis and apoptosis. On the other hand, lymphocytes represent the common protective element of immunity. NLR is more accurate than other immune markers, including TNF- $\alpha$, IL-6, or CRP. NLR is probably less affected by confounding conditions. $^{14}$

Platelets have a role in inflammation through the secretion of inflammatory and anti-inflammatory mediators, in addition to leukocytes and progenitor cells that assemble at the sites of inflammation. The PLR is an extensively used inflammatory marker in many disorders, including infections, tumors, chronic conditions, and cardiovascular diseases. ${ }^{15}$

The (MLR) is a recent, cheap, and valid marker of the systemic inflammatory response applicable and easily calculated from a WBCs assay for routine use. ${ }^{16}$ In addition, the MLR is a prognostic marker in cases of tuberculosis \& malignancies. ${ }^{17}$

Little research work has studied the interaction between psychiatric symptoms and the inflammatory process in children. Specifically, little research has explored the allying of inflammation \& ADHD in children. Anand et al. ${ }^{18}$ mentioned ratios are cost-effective and quickly accessible inflammatory mediators that can assess inflammation.

The current study aimed to get an easy objective method to detect ADHD by investigating the simple inflammatory blood ratios NLR, PRL \& MLR, for the sake of receiving early management to such cases and overcoming language affection as a comorbid symptom.

\section{METHODS}

\section{Study design}

This study was a case-control study done in the period from December 2020 to February 2021. All ADHD children engaged in this research were diagnosed as DLD. According to DSM-5, our research was conducted on two main -groups: Group 1 (SG): 70 freshly diagnosed ADHD children with DLD aged (5-12.4) years didn't receive any medications. Group 2 (HG): consisted of 44 children as the control group without $\mathrm{ADHD}$, who were physically and mentally free, with the same socio-demographic characters as group 1 .

After a complete explanation of the study, informed written consent was obtained from the caregiver/parent. Ethical approval was permitted from the Ethical Committee of Faculty of Postgraduate of Childhood Studies (FPGCS) at 2/11/2020, Ain Shams University, protocol no. RHDIRB2020110401.

\section{Inclusion criteria}

All children aged 5-13 years old were diagnosed as DLD. Diagnosis of ADHD (study group) based on Fifth Edition (DSM-5). Normal hearing, IQ above 70, and Normal motor activity, with average body mass index.

\section{Exclusion criteria}

Children with epilepsy, mental sub-normality, autism, organic brain lesions, psychiatric conditions, hematological disease, acute/chronic medical illnesses, or drug history were excluded during the last three months.

\section{Procedures}

Complete blood counting with differentiated counts has been performed for 114 children. Two $\mathrm{mL}$ of peripheral blood was collected from the cubital veins, and the serum was separated for analysis. Standardized techniques obtained serum levels of total leucocytic count (TLC), lymphocytes, monocytes, neutrophils, and platelet counts.

The inflammatory markers MLR, PLR, and NLR, were calculated manually by dividing their absolute counts according to both groups' complete blood count. Receiver operating characteristic (ROC) was applied for all children to assess inflammatory mediators NLR, MLR, and PLR to get normal cut-off values.

\section{Statistical analysis}

Statistical Package for Social Science 24 (SPSS 24) (IBM Corp., Armonk, NY, USA) was done on the collected data. ROC was done to identify the optimum cut-off values for the 
inflammatory markers. Then, descriptive statistics and Analytical statistics were applied. The chi-square test used to examine the relationship between two variables. The MannWhitney test is nonparametric test for two independent sample to evaluate variable differ between two groups. Spearman's Correlations test is nonparametric test was used to assess the strength of association between two quantitative variables.

\section{RESULTS}

The study was done on two groups: Group 1: ADHD group

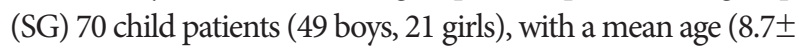
1.9 years). Group 2: control group (HC) 44 child patients (30 boys, 14 girls). With mean age ( $8.3 \pm 1.7$ years).

According to the comparative data between both groups, we found that TLC, platelets, monocytes, neutrophils and lymphocytes were in the normal range. TLC was statistically significant (0.021), platelets, monocytes and neutrophils were statistically highly significant $(0.001)$ while lymphocytes showed statistically no significant correlation (0.079).

The ROC curve was applied, and the cut-off point for inflammatory mediators was obtained as follows: NLR=1.30, $\mathrm{PLR}=93.18, \mathrm{MLR}=0.134$, which might be used for predicting

Table 1. Demographic data of the study groups

\begin{tabular}{lcc}
\hline & SG $(\mathrm{N}=70)$ & $\mathrm{HC}(\mathrm{N}=44)$ \\
\hline $\begin{array}{l}\text { Age }(\mathrm{yr}) \\
\text { Sex }\end{array}$ & $8.7 \pm 1.9$ & $8.3 \pm 1.7$ \\
$\quad$ & & \\
Male & $49(70)$ & $30(68.1)$ \\
Female & $21(30)$ & $14(31.9)$ \\
\hline
\end{tabular}

Age is presented as mean $\pm \mathrm{SD}$, while genderis presented as $\mathrm{N}(\%)$. $\mathrm{N}$, number; SG, study group; HG, healthy control group; SD, standard deviation
ADHD.

According to ROC curve cut-off points, we got the distribution of the inflammatory blood ratio among both groups. Simple blood inflammatory mediator's levels in all ADHD children were highly significant $(\mathrm{p}<0.001)$.

According to ROC curve, we assess the distribution of the simple blood inflammatory mediators among ADHD subtypes. It was 27 children (38.571\%) inattentive type (I), and 21 children (30\%) with hyperactive/impulsive type (II), \& 22 children (31,428\%) combined type (III). The MLR, PLR \& NLR levels in the ADHD subtypes of children were non-significant.

Correlations between the inflammatory markers were evaluated and were highly significant.

\section{DISCUSSION}

This study is considered the first Egyptian study to estimate the PLR, NLR \& MLR ratios as inflammatory markers in ADHD children. It is an easy objective method to detect ADHD by investigating the simple inflammatory blood ratios NLR, PRL \& MLR, to get early management to such cases and to overcome language affection as a comorbid symptom.

There were four main findings in our study. The first was obtaining the cut-off values for inflammatory blood ratios in ADHD patients. Second, there was a significant increase in inflammatory blood ratios, including PLR, NLR, \& MLR in ADHD patients. Third, no significant association was found between the inflammatory ratio and the subtypes of ADHD. Fourth, MLR was superior and common in ADHD children.

In this study (Table 1), the numbers of boys were forty-nine which were much higher than girls, the girl's numbers were twenty-one and these results were matched with Beitchman et al., ${ }^{1}$ denoting that ADHD has a gender preference 3-9 high-

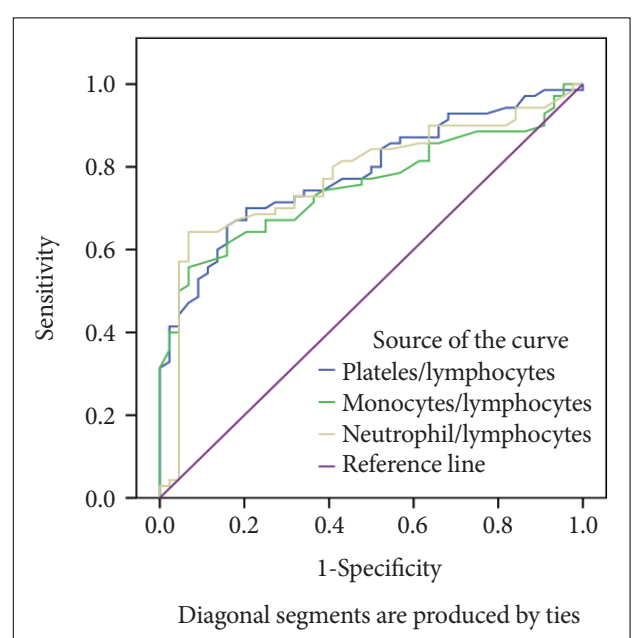

\begin{tabular}{|c|c|c|c|c|c|c|}
\hline \multicolumn{7}{|l|}{ (Area under the curve) } \\
\hline \multirow[t]{2}{*}{ Test variable (s) } & \multirow[t]{2}{*}{ Area } & \multirow{2}{*}{$\begin{array}{l}\text { Std. } \\
\text { error* }\end{array}$} & \multirow[t]{2}{*}{ p-value ${ }^{\dagger}$} & \multicolumn{2}{|c|}{$\begin{array}{c}\text { Asymptotic } \\
\text { 95\% Confidence Interval }\end{array}$} & \multirow[t]{2}{*}{ Sig } \\
\hline & & & & Lower bound & Upper bound & \\
\hline Platelets/lymphocytes & 0.79 & 0.04 & $<0.001$ & 0.704 & 0.868 & HS \\
\hline Monocytes/lymphocytes & 0.75 & 0.04 & $<0.001$ & 0.667 & 0.842 & HS \\
\hline Neutrophil/lymphocytes & 0.78 & 0.05 & $<0.001$ & 0.688 & 0.865 & HS \\
\hline
\end{tabular}

Figure 1. ROC curve and other parameters. The test result variable (s Platelets/lymphocytes, monocytes/lymphocytes, neutrophil/lymphocytes). *under the nonparametric assumption; tnull hypothesis: true area $=0.5$. NS, non-significant correlation $(p>0,05) ; S$, significant $(0.05=$ $p=0.01)$; HS, highly- significant $(p=0.01)$. 
er in boys than girls.

The sensitivity and the specificity were plotted in Figure 1, the $\mathrm{NLR}=70 \%$ \& $72.7 \%, \mathrm{PLR}=70 \%$ \& $79.5 \%, \mathrm{MLR}=72.9 \%$ \& $63.6 \%$,respectively in children with ADHD. These results matched with Avail. ${ }^{19}$

Limited studies have examined different levels of inflammatory biomarkers in ADHD children. The relation between inflammation and ADHD remains undetermined. Changed immune response, common genetic and environmental links might explain the high association between ADHD, simple blood inflammatory mediators, and assumes various underlying mechanisms.

Table 2. Comparative study between both groups (HG \& SG) regarding TLC, Platelets, monocytes, neutrophils \& lymphocytes

\begin{tabular}{lrrrrc}
\hline Group & $\mathrm{N}$ & Mean & $\mathrm{Z}$ & p-value & Sig. \\
\hline TLC $\left(4-11 \times 10^{3} / \mu \mathrm{L}\right)$ & & & 2.30 & 0.021 & $\mathrm{~S}$ \\
SG & 70 & 9471.4 & & & \\
HG & 44 & $8,625.0$ & & & \\
Platelets $\left(150-450 \times 10^{3} / \mu \mathrm{L}\right)$ & & 5.52 & $<0.001$ & HS \\
$\quad$ SG & 70 & $30,2328.6$ & & & \\
HG & 44 & $219,454.5$ & & & \\
Lymphocytes $(20-45)$ & & & 1.76 & 0.079 & NS \\
SG & 70 & 35.6 & & & \\
HG & 44 & 38.4 & & & \\
Monocytes (1-10) & & & 5.42 & $<0.001$ & HS \\
SG & 70 & 7.20 & & & \\
HG & 44 & 4.45 & & & \\
Neutrophil (40-75) & & & 6.27 & $<0.001$ & HS \\
SG & 70 & 53.6 & & & \\
HG & 44 & 40.3 & & & \\
\hline
\end{tabular}

Mann-Whitney Test. HG, healthy control group; SG, study group; TLC, total leucocytic count; NS, non-significant $(p>0.05)$; S, significant $(0.05=\mathrm{p}=0.01)$; HS, highly significant $(\mathrm{p}=0.01)$
In Table 2, shows the comparative study between both groups (HG \& SG) regarding TLC, Platelets, monocytes, neutrophils \& lymphocytes. The results of both groups were in the normal range, although statistically, the TLC was significant (0.021), and platelets, monocytes, and neutrophils were statistically highly significant differences between groups $(<0.001)$. In contrast, the lymphocytes statistically showed a non-significant correlation between them (0.079). This result explains the importance of a simple inflammatory ratio in the perspective of ADHD.

Avail, ${ }^{19}$ in his study, found that NLR was elevated in children with ADHD; this assumes that increasing the NLR levels may be accompanied by the inflammatory pathology and physiology of ADHD children. This matched hand in hand with this study's findings, which proved the increased three inflammatory ratios (PLR, NLR, \& MLR) in the ADHD children (SG) (Table 3).

Cytokines are considered valuable biomarkers but have drawbacks as they increase the cost and limit availability. Neutrophils are involved in variable inflammatory cytokines, resulting in subsequent inflammation due to cellular dysfunction in different organs by triggering this inflammatory process. ${ }^{19}$

Serati et al. ${ }^{11}$ stated a relation between cytokine levels and ADHD symptoms. IL-3 determined increased inattention symptoms, increased hyperactive-impulsive symptoms were linked to IL-6 and were positively correlated with motor activity. In contrast, oppositional symptoms were related to decreasing levels of IL-2. Although, Oades et al. ${ }^{20}$ showed a nonsignificance difference in serum IL-6 \& IL-10 in ADHD. O'Shea et al. ${ }^{21}$ Found 25 inflammation-related serum proteins among IL-6 \& 8, TNF-R1 (Tumar Necrotic Factor-Receptor one) were related to attention problems.

Platelets play a critical role in inflammation; in different disorders characterized by inflammation, mean platelet volume (MPV) levels were found to be increased. Since MPV has been

Table 3. Distribution of ADHD group and control group according to the simple blood inflammatory mediators' cut-off values (ROC curve)

\begin{tabular}{|c|c|c|c|c|c|c|}
\hline Group & $\mathrm{SG}(\mathrm{N}=70)$ & $\mathrm{HG}(\mathrm{N}=44)$ & Total $(\mathrm{N}=114)$ & $\chi^{2}$ & p-value & Sig. \\
\hline Platelets/lymphocytes & & & & 26.54 & $<0.001$ & HS \\
\hline$<93.18$ & $21(30.0)$ & $35(79.5)$ & $56(49.1)$ & & & \\
\hline$\geq 93.18$ & $49(70.0)$ & $9(20.5)$ & $58(50.9)$ & & & \\
\hline Monocytes/lymphocytes & & & & 9.29 & 0.002 & HS \\
\hline$<0.134$ & $17(24.3)$ & $23(52.3)$ & $40(35.1)$ & & & \\
\hline$\geq 0.134$ & $53(75.7)$ & $21(47.7)$ & $74(64.9)$ & & & \\
\hline Neutrophil/lymphocytes & & & & 18.83 & $<0.001$ & HS \\
\hline$<1.30$ & $21(30.0)$ & $32(72.7)$ & $53(46.5)$ & & & \\
\hline$\geq 1.30$ & $49(70.0)$ & $12(27.3)$ & $61(53.5)$ & & & \\
\hline
\end{tabular}

Data are presented as $\mathrm{N}(\%)$. Chi-square test was used to examine the relationship between two qualitative variables. NS, non-significant (p> $0.05)$; $\mathrm{S}$, significant $(0.05=\mathrm{p}=0.01)$; HS, highly- significant $(\mathrm{p}=0.01)$. ADHD, attention deficit hyperactivity disorder; ROC, receiver operating characteristic 
Table 4. Distribution between the simple blood inflammatory mediators among ADHD sub types (according to ROC curve cut-off points)

\begin{tabular}{|c|c|c|c|c|c|}
\hline Group & Below the cut of point & Above the cut of points & $\chi^{2}$ & p-value & Sig. \\
\hline Platelets/lymphocytes (49) & & & 0.241 & 0.897 & NS \\
\hline Type I (27) & $9(33.33)$ & $18(66.66)$ & & & \\
\hline Type II (21) & $6(28.57)$ & $15(71.42)$ & & & \\
\hline Type III (22) & $6(27.27)$ & $16(72.72)$ & & & \\
\hline Monocytes/lymphocytes (53) & & & 3.88 & 0.146 & NS \\
\hline Type I (27) & $9(33.33)$ & $18(66.66)$ & & & \\
\hline Type II (21) & $2(9.5)$ & $19(90.5)$ & & & \\
\hline Type III (22) & $6(27.27)$ & $16(72.72)$ & & & \\
\hline Neutrophil/lymphocytes (49) & & & 4.27 & 0.113 & NS \\
\hline Type I (27) & $12(44.44)$ & $15(55.55)$ & & & \\
\hline Type II (21) & $5(23.8)$ & $16(76.19)$ & & & \\
\hline Type III (22) & $4(18.18)$ & $18(81.81)$ & & & \\
\hline
\end{tabular}

Data are presented as $\mathrm{N}(\%)$. Chi-square test was used to examine the relationship between two qualitative variables. NS, non-significant ( $p>0.05) ;$, significant $(0.05=\mathrm{p}=0.01)$; HS, highly significant $(\mathrm{p}=0.01)$. ADHD, attention deficit hyperactivity disorder; ROC, receiver operating characteristic

Table 5. Intercorrelation between inflammatory blood ratio

\begin{tabular}{|c|c|c|c|}
\hline & $\begin{array}{c}\text { Platelets/ } \\
\text { lymphocytes }\end{array}$ & $\begin{array}{l}\text { Monocytes/ } \\
\text { lymphocytes }\end{array}$ & $\begin{array}{l}\text { Neutrophil/ } \\
\text { lymphocytes }\end{array}$ \\
\hline \multicolumn{4}{|c|}{ Neutrophil/lymphocytes } \\
\hline rho & $0.44^{*}$ & $0.44^{*}$ & 1.0 \\
\hline $\mathrm{p}$-value & $<0.001$ & $<0.001$ & - \\
\hline Sig. & HS & HS & - \\
\hline \multicolumn{4}{|c|}{ Monocytes/lymphocytes } \\
\hline rho & $0.45^{*}$ & 1.0 & \\
\hline $\mathrm{p}$-value & $<0.001$ & - & \\
\hline Sig. & HS & - & \\
\hline \multicolumn{4}{|c|}{$\begin{array}{l}\text { Spearman Correlation. *significance. "rho" defines the strength and } \\
\text { direction of the relationship between two variables. NS, non-signif- } \\
\text { icant }(\mathrm{p}>0.05) ; \mathrm{S} \text {, significant }(0.05=\mathrm{p}=0.01) \text {; HS, highly significant } \\
(\mathrm{p}=0.01)\end{array}$} \\
\hline
\end{tabular}

considered an inflammatory marker, this suggests that the PLR, NLR, and MLR values could be used as markers of inflammation in ADHD children.

York et al. ${ }^{22}$ Found increased MPV values in children. Similar to the results of Avail..$^{19}$ This, concurrent with our study demonstrated a marked increase in platelet level in ADHD children (Table 3).

No statistically significant relation was found between simple blood inflammatory mediators \& the different ADHD subtypes (Table 4). This suggests that raised inflammation is related to the diagnosis of ADHD \& does not essentially correlate to the same aspect's seriousness. This agrees with Avail, ${ }^{19}$ who found no significant correlation between the inflammatory ratios and the ADHD subtypes in his study.

Table 5 showed that the intercorrelation between simple blood inflammatory mediators was highly significant, which explained the idea that inflammation is either the cause of ADHD or plays a comorbid role in ADHD.

This study found a new objective way for early detection and confirmation of the diagnosis of ADHD cases from all of the above. There is the fact that the thinking, attention, learning process, and social interaction of the ADHD children were affected, which are considered basic factors in the development of language. ${ }^{23}$ Some factors induce and aggravate the proper language development as follows:

1) The ADHD children hadn't a proper stimulating environment for adequate language development; ${ }^{24}$ those children were neglected with negative maternal comments and negative expressed emotions, which aggravate ADHD severity.

2) Dopamine and norepinephrine as neurotransmitters play an essential role in the interconnection of different subsystems in the brain.

3)The impairments in the working memory affected the language impairments. ${ }^{25}$

4) The frontal lobe and basal ganglia as neuroanatomical origins were claimed to affect both ADHD and language disorders. ${ }^{26}$

Mazza et al. ${ }^{27}$ found that the non-affective psychosis in adults had a significantly higher NLR and MLR. Kirlioglu et al. ${ }^{28}$ reported that NLR and MLR were elevated during manic episodes in bipolar patients compared with mixed states.

Our study had several limitations. First, we focused on the relationship between PLR, NLR\& MLR, and inflammation without follow-up after rehabilitation. Second, the sample size was small. So, we couldn't determine the cause-effect details from our findings. Third, other inflammatory markers such 
as cytokines and ILs were not assessed. Fourth, neutrophils have a short life span and variable counts between different individuals. Therefore, it was hard to determine whether the increased inflammatory ratios were unconventional indices of changes in the immunity of ADHD children.

The study concluded that the picture of inflammatory pathways in ADHD patients is complex. However, a simple calculation of the inflammatory blood ratio can predict ADHD. Further randomized and controlled studies evaluating the relationship between inflammatory blood ratio and ADHD patients are needed. This study explained that it is important to consider language abilities when assessing children with ADHD. The screening tools for inflammatory markers are essential when dealing with $\mathrm{ADHD}$ children with/without DLD. Also, working memory assessment is mandatory in ADHD with DLD to assign a special program in language therapy for each child.

\section{Availability of Data and Material}

The datasets generated or analyzed during the study are available from the corresponding author on reasonable request.

\section{Conflicts of Interest}

The authors have no potential conflicts of interest to disclose.

\section{Author Contributions}

Conceptualization: Reham Ahmed Fahiem, Lamis H Mekkawy. Data curation: Reham Ahmed Fahiem, Lamis H Mekkawy. Formal analysis: Reham Ahmed Fahiem, Lamis H Mekkawy. Funding acquisition: Reham Ahmed Fahiem, Lamis H Mekkawy. Investigation: Reham Ahmed Fahiem, Lamis H Mekkawy. Methodology: Reham Ahmed Fahiem, Lamis H Mekkawy. Project administration: Reham Ahmed Fahiem, Lamis H Mekkawy. Resources: Reham Ahmed Fahiem, Lamis H Mekkawy. Software: Reham Ahmed Fahiem, Lamis H Mekkawy. Supervision: Reham Ahmed Fahiem, Lamis H Mekkawy. Validation: Reham Ahmed Fahiem, Lamis H Mekkawy. Visualization: Reham Ahmed Fahiem, Lamis H Mekkawy. Writing-original draft: Reham Ahmed Fahiem, Lamis H Mekkawy. Writing-review \& editing: Reham Ahmed Fahiem, Lamis H Mekkawy.

\section{ORCID iDs}

Reham Ahmed Fahiem

Lamis H Mekkawy

https://orcid.org/0000-0003-2622-5956 https://orcid.org/0000-0001-8413-7466

\section{Funding Statement \\ None}

\section{REFERENCES}

1. Beitchman JH, Wilson B, Johnson CJ, Atkinson L, Young A, Adlaf E. Fourteen-year follow-up of speech/language-impaired and control children: psychiatric outcome. J Am Acad Child Adolescent Psychiatry 2001; 40:75-82.

2. Willcutt EG. The prevalence of DSM-IV attention-deficit/hyperactivity disorder: a meta-analytic review. Neurotherapeutics 2012;9:490-499.

3. Wolraich ML, Hagan JF Jr, Allan C, Chan E, Davison D, Earls M, et al. Children subcommittee on, and disorder adolescents with attentiondeficit/hyperactive. Clinical practice guideline for the diagnosis, evaluation, and treatment of attention-deficit/hyperactivity disorder in children and adolescents. Pediatrics 2019;144:e20192528.
4. American Psychiatric Association. Diagnostic and Statistical Manual of Mental Disorders. Washington DC: American Psychiatric Publishing; 2013.

5. Heyer JL. Responsibilities of speech pathologists toward children with ADHD. Semin Speech Lang 1995;16:275-288.

6. Rappaport GC, Orony A, Tenenbaum A. Is early intervention effective in preventing ADHD? Isr J Psychiatry Relate Sci 1998;35:271-279.

7. Quan N, Banks WA. Brain-immune communication pathways. Brain Behav Immun 2007;21:727-735.

8. Leffa DT, Torres ILS, Rohde LA. A review on the role of inflammation in attention-deficit/hyperactivity disorder. Neuroimmunomodulation 2018;25:328-333.

9. Furtado M, Van Lieshout RJ, Van Ameringen M, Green SM, Frey BN. Biological and psychosocial predictors of anxiety worsening in the postpartum period: a longitudinal study. J. Affect Disord 2019;250:218-225.

10. Darwish AH, Elgohary TM, Nosair NA. Serum interleukin- in-6 level in children with attention-deficit hyperactivity disorder (ADHD). J Child Neurol 2019;34:61-67.

11. Serati M, Barkin JL, Orsenigo G, Altamura AC, Buoli M. Research review: the role of obstetric and neonatal complications in childhood attention deficit and hyperactivity disorder-a systematic review. J Child Psychol Psychiatry 2017;58:1290-1300.

12. Banks WA, Erickson MA. The blood-brain barrier and immune function and dysfunction. Neurobiol Dis 2010;37:26-32.

13. Çakır U, Tuman TC, Yıldırım O. Increased neutrophil/lymphocyte ratio in patients with bipolar disorder: a preliminary study. Psychiatr Danub 2015;27:180-184.

14. Azab B, Zaher M, Weiserbs KF, Torbey E, Lacossiere K, Gaddam S, et al. Usefulness of neutrophil to lymphocyte ratio in predicting shortand long-term mortality after non-ST-elevation myocardial infarction. Am J Cardiol 2010;106:470-476.

15. Topal E, Celiksoy MH, Catal F, Karakoç HT, Karadag A, Sancak R. The platelet parameters as inflammatory markers in preschool children with atopic eczema. Clin Lab 2015;61:493-496.

16. Ji H, Li Y, Fan Z, Zuo B, Jian X, Li L, et al. Monocyte/lymphocyte ratio predicts the severity of coronary artery disease: a syntax score assessment. BMC Cardiovasc Disord 2017;17:90.

17. Neofytou K, Smyth EC, Giakoustidis A, Khan AZ, Williams R, Cunningham $\mathrm{D}$, et al. The preoperative lymphocyte-to-monocyte ratio is prognostic of clinical outcomes for patients with liver-only colorectal metastases in the neoadjuvant setting. Ann Surg Oncol 2015;22:4353-4362.

18. Anand D, Colpo GD, Zeni G, Zeni CP, Teixeira AL. Attention-deficit/ hyperactivity disorder and inflammation: What does current knowledge tell us? A systematic review. Front Psychiatry 2017;8:228.

19. Avail S. Evaluation of the neutrophil/lymphocyte ratio, platelet/lymphocyte ratio, and mean platelet volume as inflammatory markers in children with attention-deficit hyperactivity disorder Psychiatry Clin Neurosci 2018;72:522-530.

20. Oades RD, Dauvermann MR, Schimmelmann BG, Schwarz MJ, Myint AM. Attention-deficit hyperactivity disorder (ADHD) and glial integrity: S100B, cytokines and kynurenine metabolism effects of medication. Behav Brain Funct 2010;6:29.

21. O'Shea TM, Joseph RM, Kuban KC, Allred EN, Ware J, Coster T, et al. Elevated blood levels of inflammation-related proteins are associated with an attention problem at age 24 mo in extremely preterm infants. Pediatr Res 2014;75:781-787.

22. York O, Mutlu C, Tanju IA, Celik D, Ozcan O. Mean platelet volume in children with attention deficit hyperactivity disorder. Med Hypotheses 2014;82:341-345.

23. Rutter M. The role of cognition in child development and disorder. Br J Med Psychol 1987;60:1-16.

24. Psychogiou L, Daley DM, Thompson MJ, Sonuga-Barke EJ. Do maternal attention-deficit/hyperactivity disorder symptoms exacerbate or ameliorate the negative effect of child attention-deficit/hyperactivity disorder symptoms on parenting? Dev Psychopathol Winter 2008;20:121-137. 
25. Cohen NJ, Vallance DD, Barwick M, Im N, Menna R, Horodezky NB. The interface between ADHD and language impairment: an examination of language, achievement, and cognitive processing. J Child Psychol Psychiatry 2000;41:353-362.

26. Williams D, Stott CM, Goodyer IM, Sahakian BJ. Specific language impairment with or without hyperactivity: Neuropsychological evidence for frontostriatal dysfunction. Develop Med Child Neurol 2000;42:368-375.

27. Mazza MG, Lucchi S, Rossetti A, Clerici M. Neutrophil-lymphocyte ra- tio, monocyte-lymphocyte ratio and platelet-lymphocyte ratio in nonaffective psychosis: a meta-analysis and systematic review. World J Biol Psychiatry 2020;21:326-338.

28. Kirlioglu SS, Balcioglu YH, Kalelioglu T, Erten E, Karamustafalioglu N. Comparison of the complete blood count-derived infl ammatory markers in bipolar patients with manic and mixed episodes. Bratislava Med J 2019;120:195-199. 